\title{
Knight Cancer Institute
}

National Cancer Institute

\section{Source}

National Cancer Institute. Knight Cancer Institute. NCI Thesaurus. Code C39343.

The mission of the Knight Cancer Institute is to translate discoveries into better ways to diagnose, prevent, and treat cancer. It became an $\mathrm{NCl}$-designated Cancer Center in 1997. 